\title{
Dihydrotestosterone interacts with EGFR/MAPK signalling and modulates EGFR levels in androgen receptor-positive $\mathrm{LNCaP}$ prostate cancer cells
}

\author{
BISWAJIT MUKHERJEE ${ }^{1}$ and DORIS MAYER \\ Hormones and Signal Transduction Group, German Cancer Research Centre, \\ Im Neuenheimer Feld 280, D-69120 Heidelberg, Germany
}

Received March 26, 2008; Accepted May 23, 2008

DOI: 10.3892/ijo_00000048

\begin{abstract}
Androgen receptor (AR) signalling plays a pivotal role in prostate cancer pathogenesis and progression. However, androgen-mediated AR signalling is yet to be fully understood. EGFR and MAP kinase signalling pathways play predominant roles in AR function. Therefore, we investigated the interaction of EGFR signalling and AR activity in AR-positive LNCaP cells. We found that $5 \alpha$-dihydrotestosterone (DHT) and EGF had a synergistic effect on AR activity as detected by a luciferase reporter system, although EGF alone did not activate AR. Both ERK1/2 and p38 were involved in DHT and DHT/EGF-induced AR activation as detected by specific MEK and p38 inhibitors. Furthermore, 24-h treatment of the cells with DHT resulted in ubiquitination and downregulation of the EGFR. This effect could be inhibited by the anti-androgen flutamide, suggesting an androgen-dependent mechanism. On the other hand, DHT-treatment strongly increased AR levels in LNCaP cells. These data suggest a complex regulatory loop between activated AR and EGFR. In conclusion, activation of AR by both DHT and EGF/DHT involves the MAP kinase pathway. Long-term activation of AR results in increase of AR levels, which through so far unknown regulatory mechanisms results in ubiquitination and degradation of the EGFR.
\end{abstract}

Correspondence to: Dr Doris Mayer, Hormones and Signal Transduction, German Cancer Research Centre, Im Neuenheimer Feld 280, D-69120 Heidelberg, Germany

E-mail: d.mayer@dkfz-heidelberg.de

Present address: ${ }^{1}$ Department of Pharmaceutical Technology, Jadavpur University, Kolkata (Calcutta) 700 032, India

Abbreviations: AR, androgen receptor; DHT, dihydrotestosterone; EGF, epidermal growth factor; EGFR, EGF receptor; ERK, extracellular signal-regulated kinase; FL, flutamide; MAPK, mitogen-activated protein kinase; MEK, MAP-ERK kinase; PI3K, phosphatidylinositol 3-kinase; PKC, protein kinase C; TGF, transforming growth factor

Key words: interaction of androgen receptor and EGF receptor, MAP kinase, ERK1/2, p38, EGFR ubiquitination, prostate cancer

\section{Introduction}

Prostate cancer is among the most frequently diagnosed cancers in males in the Western world (1). Although the molecular events involved in the development of prostate cancer are not well understood, there is general agreement that the androgen receptor (AR) plays a key role in the development, continued survival and proliferation of prostate cancer cells (2).

Proliferation and growth of androgen-dependent prostate cancer cells is mediated by the AR, a ligand-dependent nuclear receptor and transactivation factor. Binding of androgens such as dihydrotestosterone (DHT) to AR promotes the activation of protein kinases which phosphorylate several serine residues on AR. Some of these phosphorylations stabilize AR-homodimers, and the others influence transactivation properties $(3,4)$. The involvement of androgens in promotion of prostate tumour growth is explained by a generally accepted mechanism in which the ligand-bound receptor is phosphorylated, dimerised and translocated to the nucleus where it regulates the expression of genes involved in proliferation and survival (4). AR-positive prostate cancer is often treated by anti-androgenic therapy. However, presence of mutations on AR gene in prostate cancer cells may result in androgen-independent phenotype of the cells (5).

Involvement of epidermal growth factor receptor (EGFR) signal transduction pathway in pathogenesis, growth and metastasis in various cancers including prostate cancer is widely known (6-9). EGFR (ErbB1) belongs to the family of transmembrane receptor protein tyrosine kinases. The other members of the EGFR sub-family are ErbB2, ErbB3 and ErbB4. These receptors play a pivotal role in regulating cell proliferation, differentiation and transformation, and blocking of the EGFR pathway inhibits the proliferation of the cancer cells (10). Deregulation of EGFR has been reported to be involved in the transition of hormone dependent to hormone refractory state of prostate cancer cells (6). 'Cross-talk' of the EGFR signalling with AR has been postulated as a potential mechanism to activate AR in prostate cancer (11). EGFR activation results in downstream protein kinase $\mathrm{C}-\delta$ (PKC- $\delta$ ) signalling, representing a mechanism which is known to be critical for prostate cancer invasiveness (12). Two other important pathways, mitogen activated protein kinases (MAPK) and phosphatidylinositol 3-kinase $(\mathrm{PI} 3 \mathrm{~K}) / \mathrm{AKT}$, are also activated by $\operatorname{EGFR}(10,13)$, and 
activation of MAPK as an event depending on EGFR function in prostate cancer has been reported (13-15). Presence of EGF and transforming growth factor- $\alpha$ (TGF- $\alpha$ ), the natural ligands and potent activators of EGFR, has been observed in many human tumours including prostate cancer $(6,9,13,16,17)$. The reliance of prostate cancer pathogenesis on the activated EGFR and its downstream signalling pathways PI3K/AKT and/or MAPK is not completely elucidated (18). The major members of the MAPK family are ERK $1 / 2$ and p38. ERK1/2 contribute to cell differentiation, proliferation and survival whereas $\mathrm{p} 38$, a down-stream effector of PKC- $\delta$, has been reported to promote apoptosis (19). However, many contradictory findings confound the roles of ERK and p38. ERK activation has been correlated with prostate cancer progression in line with Gleason score (20), while decline in ERK activities in advanced malignant prostate cancer has also been reported (21). Likewise, some authors $(19,22)$ have suggested that p38 plays an important role in induction of apoptosis, while others (23) reported that the apoptotic rate in LNCaP cells increased significantly following p38 inhibition. Effects of p38, in particular, on prostate cancer cells are therefore complex (24). Further, reduction of EGFR protein levels has been observed in DU145-AR cells long-term treated with androgens (25). EGFR-stimulated intracellular signalling involving the MAPK pathway and the potential cross-talk between EGFR and AR demand further studies to elucidate the mechanism linking EGFR and AR signalling pathways in prostate cancer pathogenesis. The aim of the present study was to investigate the involvement of the EGFRMAPK pathway in AR signalling in androgen-dependent prostate cancer, taking LNCaP cells as a model, and to clarify the mechanisms related to the modulation of EGFR protein expression in androgen treated condition.

\section{Materials and methods}

Reagents, antibodies and plasmid. The proteasome inhibitor MG-132, U0126, a specific inhibitor of MEK1/2, and the p38 inhibitor SB203580 were from Calbiochem (Merck Biosciences, Darmstadt, Germany). Protein A-sepharose beads were from Sigma (München, Germany). EGF was from R\&D Systems GmbH (Wiesbaden, Germany), DHT and flutamide (FL) from Sigma (Steinheim, Germany). Antibodies used were against androgen receptor (AR) [AR(441): mouse antibody against amino acids 299-315 of AR of human origin (sc 7305 Santa Cruz Biotechnology, Heidelberg, Germany)]; EGFR [(Ab-1), mouse, Calbiochem]; phosphorylated p38 [pp38 (Thr180/Tyr182), rabbit, Cell Signaling Technology (Danvers, MA, USA)], p38 protein (New England Biolabs, Beverly, MA, USA); phosphorylated ERK1/2 and ERK1/2 proteins [pp44/42 and p44/42, rabbit, (Cell Signaling Technology)], ß-tubulin (mouse, Upstate Biotechnology, Lake Placid, CA, USA), B-actin (mouse, Abcam, Cambridge, UK) and ubiquitin (rabbit, Dako, Hamburg, Germany). Horseradish peroxidase-conjugated anti-mouse and anti-rabbit secondary antibodies were from Dianova (Hamburg, Germany). Amersham ECLplus Western Blotting detection reagent was from GE Healthcare (Freiburg, Germany), and radiographic film (Konika Minolta) was purchased from Hartenstein (Würzburg, Germany). The plasmid PLC0546A containing luciferase under the control of androgen response element (AREluc) was described previously (26).

Cell culture and treatment procedure. $\mathrm{LNCaP}$ cells were grown for 7 days in phenol-red free RPMI-1640 medium (PAA Laboratories, Cölbe, Germany) supplemented with penicillinstreptomycin and $10 \%$ foetal calf-serum (FCS) stripped with dextran-charcoal (27). Before experimental treatments cells were kept overnight in the same medium supplemented with $2 \%$ stripped FCS.

Transfection. LNCaP cells $\left(2 \times 10^{5}\right.$ cells/well $)$ were plated in RPMI - 10\% stripped FCS in 6-well plates. Transfection of the plasmid PLC0546A, $0.05 \mu \mathrm{g} /$ well, was conducted the next day using effectene (Qiagen $\mathrm{GmbH}$, Hilden, Germany) according to the procedure recommended by the manufacturer. After $24 \mathrm{~h}$, the cells were washed with sterile PBS and RPMI containing $2 \%$ charcoal-stripped FCS was added. Another $24 \mathrm{~h}$ later, cells were used for further treatments.

Preparation of cell lysates and Western blot analysis. LNCaP cells were treated with DHT (1-5 nM), EGF (10 ng/ml), FL $(1 \mu \mathrm{M})$ and combinations thereof for $15 \mathrm{~min}$. After treatment, the cells were washed with ice-cold phosphate-buffered saline (PBS) and scraped in PBS. The cell suspension was centrifuged and cell pellets were snap-frozen in liquid nitrogen. Thereafter, the pellets were suspended in lysis buffer (27) and incubated on ice for $30 \mathrm{~min}$. The samples were then centrifuged at $13,000 \mathrm{x} \mathrm{g}$ for $10 \mathrm{~min}$ at $4^{\circ} \mathrm{C}$ and the supernatants (lysates) were submitted to SDS-PAGE and Western blot analysis. Protein concentrations were determined using the DC Protein Assay kit from Bio-Rad (München, Germany). Some of the Western blot analyses were quantitatively evaluated using the ImageJ software (NIH, USA).

Measurement of luciferase activities. AREluc-transfected LNCaP cells were treated with DHT (5 nM), EGF (10 ng/ml), SB $203580(20 \mu \mathrm{M})$ or U0126 $(20 \mu \mathrm{M})$ and combinations thereof, or left untreated for controls. Luciferase activity was measured using the firefly luciferase reagents from Promega (Mannheim, Germany) and a Biolumat LB 9505 (Berthold, Bad Wildbad, Germany).

Immunoprecipitation and detection of ubiquitination of EGFR protein. LNCaP cells were treated with DHT (5 nM), FL $(1 \mu \mathrm{M}), \mathrm{MG}-132(5 \mu \mathrm{M})$, and combinations thereof, for $6 \mathrm{~h}$. MG-132 was added $1 \mathrm{~h}$ prior to the other compounds. The EGFR protein was immunoprecipitated from the lysate with $2 \mu \mathrm{g}$ EGFR antibody for $12 \mathrm{~h}$ at $4^{\circ} \mathrm{C}$ using protein $\mathrm{A}$ sepharose beads. The immunocomplexes collected on the beads were washed with lysis buffer and were extracted in SDS loading buffer (10 mM Tris, $\mathrm{pH} 6.8,2 \%$ SDS, 5\% glycerol, $0.01 \%$ bromophenol blue, $0.35 \mathrm{M} ß$-mercaptoethanol). After denaturation and centrifugation, the samples were separated in SDS-PAGE and used for Western blot analysis using ubiquitin antibodies and, after stripping of the membrane, EGFR antibodies.

Statistical analyses. The data were analysed statistically using paired t-tests with the help of Medcalc software (Medcalc 
A

$\begin{array}{lllllllll}\operatorname{DHT}(5 \mathrm{nM}, 15 \mathrm{~min}) & - & + & - & + & - & + & - & + \\ \mathrm{FL}(1 \mu \mathrm{M}, 15 \mathrm{~min}) & - & - & - & - & + & + & + & + \\ \mathrm{EGF}(10 \mathrm{ng} / \mathrm{ml}, 15 \mathrm{~min}) & - & - & + & + & - & - & + & +\end{array}$

pERK $1 / 2$

ERK $1 / 2$

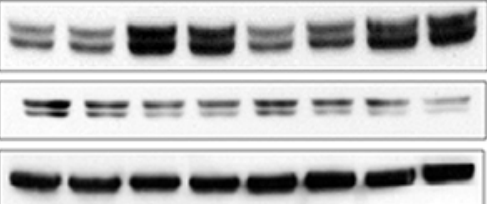

B

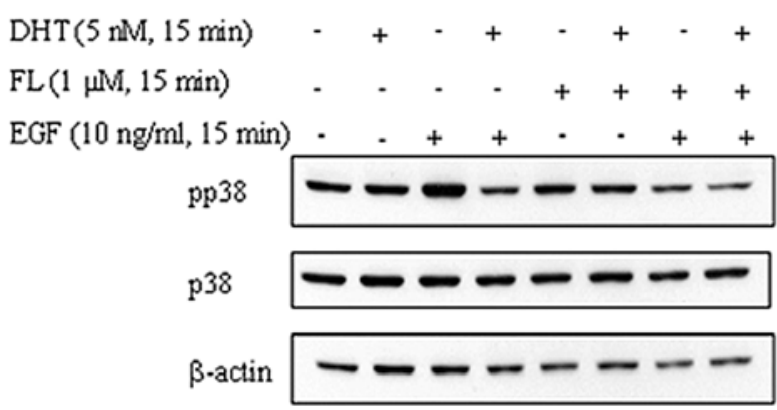

Figure 1. Influence of EGF, DHT and flutamide (FL) on MAPK pathway. LNCaP cells were treated with DHT, FL, EGF and combinations thereof. Untreated LNCaP cells were used as control. (A) Total protein $(20 \mu \mathrm{g})$ from each cell lysate was analysed by Western blotting with anti-phosphoERK $1 / 2$ and anti-ERK $1 / 2$ antibodies. B-tubulin was used to ensure equivalent loading of the gel incubating the same membrane with $\beta$-tubulin antibody after stripping. (B) Detection of p38 phosphorylation in the same lysates as shown in (A). As the loading control, anti-ß-actin antibody was used.
Software, Mariakerke, Belgium). A p $<0.05$ was considered as statistically significant.

\section{Results}

Effect of DHT treatment on ERK and p38 phosphorylation. We first evaluated the effect of $5 \mathrm{nM}$ DHT short-term treatment (15 $\mathrm{min}$ ) on activation of MAPK pathway by investigating the phosphorylation status of ERK1/2 and p38 in LNCaP cells. Treatment with $10 \mathrm{ng} / \mathrm{ml}$ EGF used as control resulted in strong phosphorylation of ERK1/2 and p38. DHT-treatment did not cause phosphorylation of ERK1/2 and p38 (Fig. 1). Interestingly, treatment of the cells with $5 \mathrm{nM}$ DHT reduced EGF-induced p38 phosphorylation, and treatment with $1 \mu \mathrm{M}$ FL reduced the EGF-induced p38-phosphorylation below the basal phosphorylation level observed in untreated controls (Fig. 1B).

Effect of DHT and EGF on AR activity. We next explored the role of the activation of the MAPK pathway on AR activity. AR activation was measured by induction of firefly luciferase activity using AREluc as a reporter. Using DHT-treatment as control, we found a rapid 7 -fold induction of luciferase activity after $3 \mathrm{~h}$ of treatment (Fig. 2A). The induction was transient, after $24 \mathrm{~h}$ DHT-treatment only 2-fold luciferase induction was measured (Fig. 2B). EGF alone had no effect on AR transactivation, however, a combination treatment of the cells with $5 \mathrm{nM}$ DHT and $10 \mathrm{ng} / \mathrm{ml}$ EGF resulted in significantly stronger AR activation compared to DHT alone, about 40 and $15 \%$ higher luciferase activity were detected upon 3- and 24-h treatments, respectively. Both induction
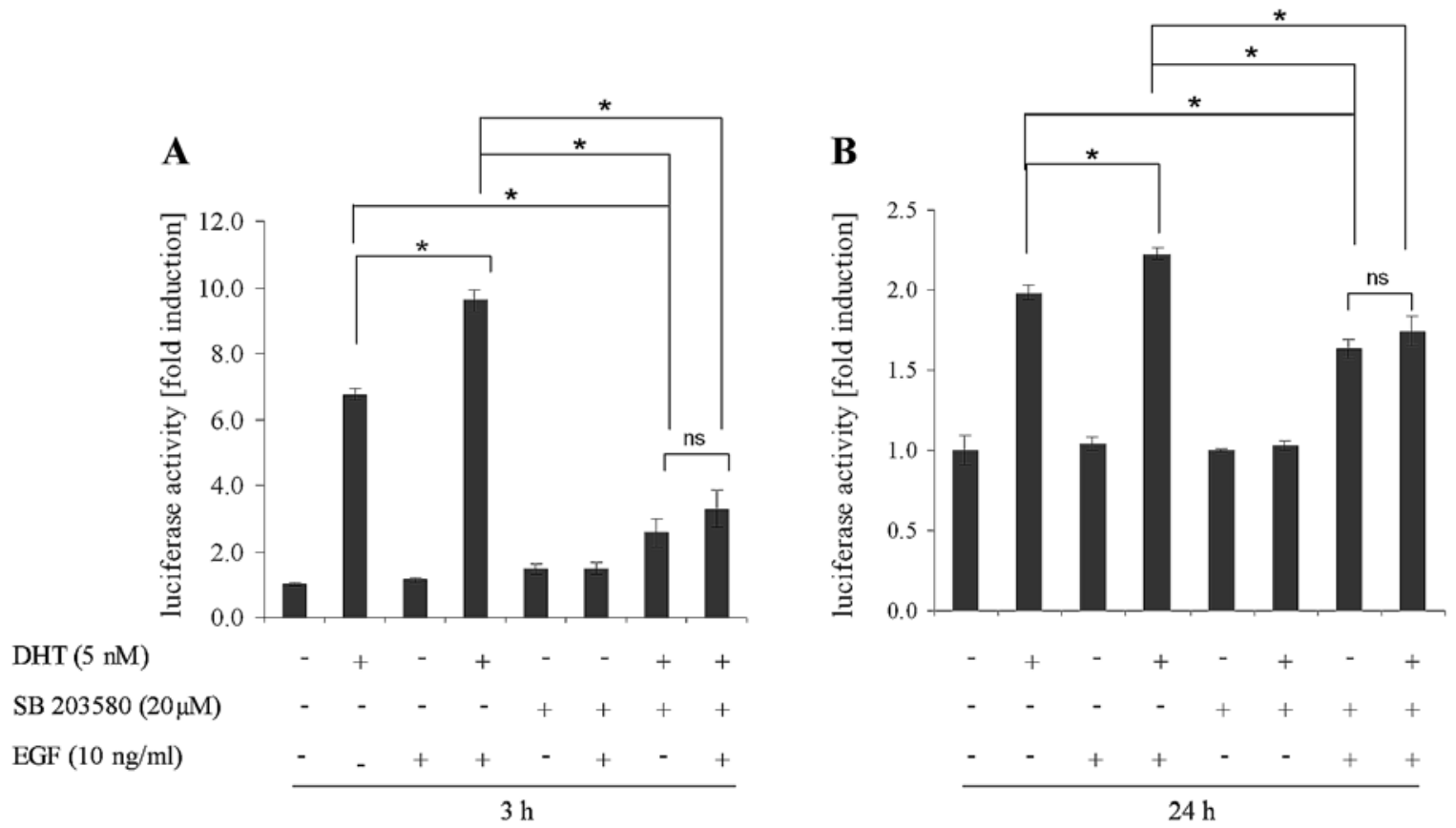

Figure 2. Influence of EGF-administration and p38-inhibition on DHT-induced ARE-dependent induction of luciferase in LNCaP cells. AR activation was measured by luciferase activity assays using AREluc as a reporter. Twenty-four hours after transfection with AREluc, LNCaP cells were treated with $5 \mathrm{nM}$ DHT, $10 \mathrm{ng} / \mathrm{ml}$ EGF, $20 \mu \mathrm{M}$ SB203580 and combinations thereof, for $3 \mathrm{~h}$ (A) or for $24 \mathrm{~h}$ (B). Data are expressed as a fold induction of luciferase activity measured against the untreated AREluc transfected LNCaP cells. Data indicate mean \pm SD from two independent sets of experiments (four measurements). ${ }^{*} \mathrm{p}<0.05 ;$ ns, statistically non-significant. 


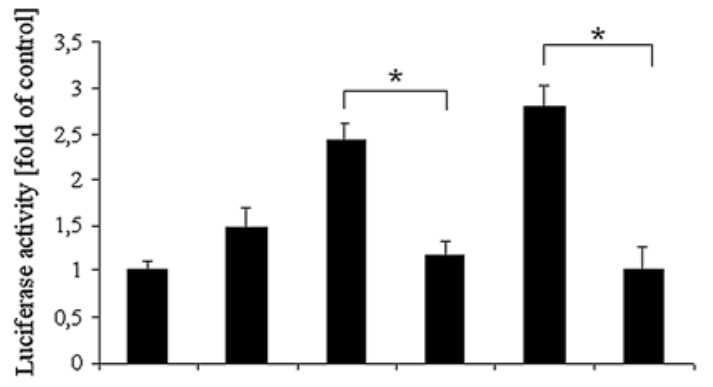

$\operatorname{DHT}(5 \mathrm{nM}) \quad-\quad . \quad+\quad+\quad+\quad+$ $\mathrm{U} 0126(20 \mu \mathrm{M}) \quad-\quad+\quad+\quad+\quad+\quad+$

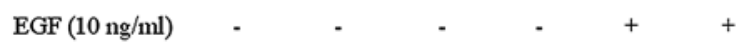

Figure 3. Influence of EGF-administration and MEK-inhibition on DHTinduced ARE-dependent induction of luciferase in LNCaP cells. AR activation was measured by luciferase activity assays using AREluc as a reporter. Twenty-four hours after transfection with AREluc, LNCaP cells were treated with $5 \mathrm{nM}$ DHT, $10 \mathrm{ng} / \mathrm{ml}$ EGF and $20 \mu \mathrm{M}$ U0126 and combinations thereof, for $24 \mathrm{~h}$. Data are expressed as a fold induction of luciferase activity measured against the untreated AREluc transfected LNCaP cells. Data indicate mean \pm SD from two independent sets of experiments (four measurements). ${ }^{*} \mathrm{p}<0.05$.

A

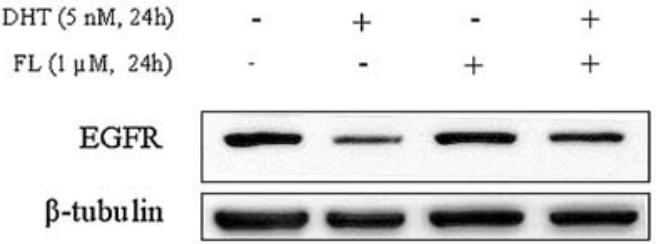

B

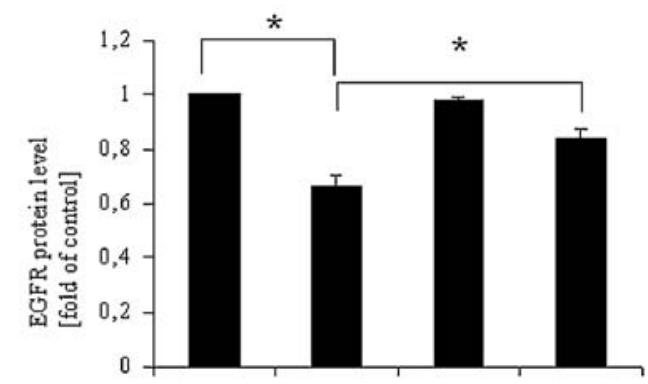

Figure 4. Reduction of EGFR protein levels by DHT-treatment in LNCaP cells. (A) Cells were treated with $5 \mathrm{nM} \mathrm{DHT}, 1 \mu \mathrm{M}$ FL and DHT/FL for $24 \mathrm{~h}$, and untreated cells were considered as control. EGFR protein was detected by immunoblotting. (B) Quantitative evaluation of immunoblots. EGFR protein level was presented as a fold of control. Data show mean \pm $\mathrm{SD}$ of two independent sets of experiments. ${ }^{*} \mathrm{p}<0.05$. of luciferase with DHT and DHT/EGF were significantly inhibited by the anti-androgen FL (not shown). The finding strongly claims that DHT and EGF synergistically induce AR signalling. Treatment of the cells with the specific p38inhibitor SB 203580 caused significant reduction of both DHT- and DHT-EGF-induced luciferase activities after 3 and 24-h incubation (Fig. 2). This inhibition further indicates involvement of $\mathrm{p} 38 \mathrm{MAPK}$ in AR signalling.

To detect the role of ERK $1 / 2$ on AR-transactivation by DHT and EGF/DHT, U0126, a specific inhibitor of MEK which is an upstream regulator of ERK1/2, was used to inhibit phosphorylation of ERK1/2. Treatment of AREluc-transfected LNCaP cells with $20 \mu \mathrm{M}$ U0126 reduced significantly DHT- and EGF/DHT-induced luciferase activities (Fig. 3). The results indicate interaction of ERK1/2 signalling with AR-transactivation. However, U0126 alone showed a small enhancement of luciferase activity as compared to control, which indicates that U0126 may affect AR-transactivation in LNCaP cells by other, so far unkown mechanisms.

These data suggest that EGF-activated MAPK pathway alone does not result in measurable AR activation in our cells, however, together with DHT, EGF shows a strong synergistic effect on AR activity.

DHT treatment reduces EGFR protein levels. Data presented so far suggest that activation of the EGFR and the EGFRsignalling pathway are related to AR activity. As long-term treatment with DHT was reported to reduce EGFR protein level in DU145-AR cells (25), we investigated the effect of DHT on EGFR in our experimental system. DHT treatment for $24 \mathrm{~h}$ was found to decrease EGFR levels significantly (Fig. 4) and the decreased levels of the protein were rescued by the anti-androgen FL. Therefore, to investigate the mechanism leading to decreased EGFR protein levels in presence of DHT, LNCaP cells were treated with $5 \mathrm{nM}$ DHT, $1 \mu \mathrm{M}$ FL, and the potent cell-permeable proteasome inhibitor MG-132 $(5 \mu \mathrm{M})$ and combinations thereof. Incubation with MG-132 inhibits the proteasomal degradation of ubiquitin-conjugated proteins in mammalian cells. Since a report suggests that MG-132 provides maximal effect between 6-12 h (28), we accordingly selected 6 -h treatment-duration. EGFR protein was immunoprecipitated from cell lysates and ubiquitination was detected with anti-ubiquitin antibody in Western blot analyses. Fig. 5 shows that in LNCaP cells, DHT treatment increased ubiquitination of EGFR markedly. Combination

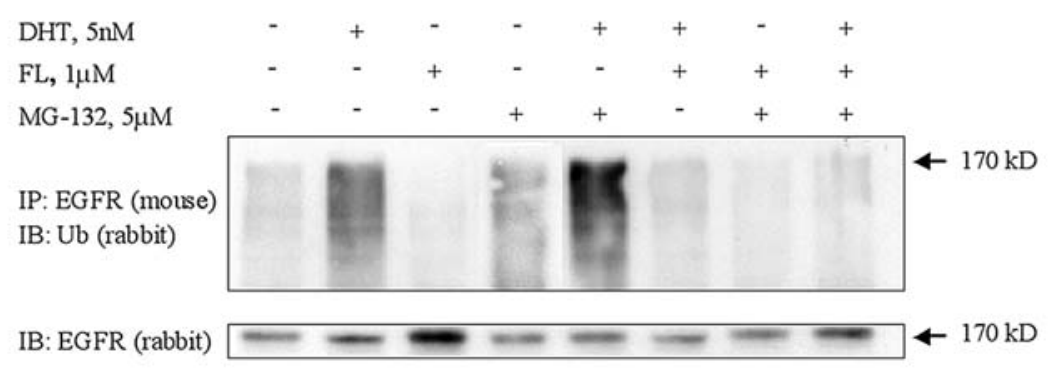

Figure 5. DHT induces polyubiquitination of EGFR protein. LNCaP cells were treated with $5 \mathrm{nM}$ DHT, $1 \mu \mathrm{M}$ FL, $5 \mu \mathrm{M}$ MG-132 and combinations, for $6 \mathrm{~h}$ except MG-132 which was always added $1 \mathrm{~h}$ before the other compounds. EGFR protein was immunoprecipitated with EGFR antibody (mouse) and the precipitated protein was subjected to Western blot analysis with anti-ubiquitin antibody (Ub) (upper panel). The same blot was used to detect EGFR protein with anti-EGFR (rabbit) antibody after stripping (lower panel). The data are the representatives of two independent experiments. 


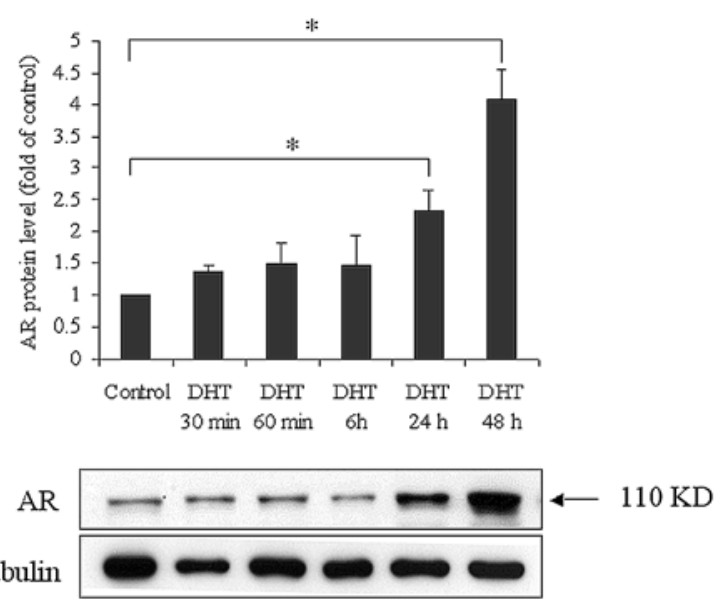

Figure 6. AR protein level in LNCaP cells at different time-points of DHT treatment. LNCaP cells were treated with $5 \mathrm{nM}$ DHT for $30 \mathrm{~min}, 60 \mathrm{~min}$, $6 \mathrm{~h}, 24 \mathrm{~h}$ and $48 \mathrm{~h}$. AR was detected by Western blotting. B-tubulin was detected as loading control. Data indicate the mean \pm SD of two independent sets of experiments. ${ }^{*} \mathrm{p}<0.05$.

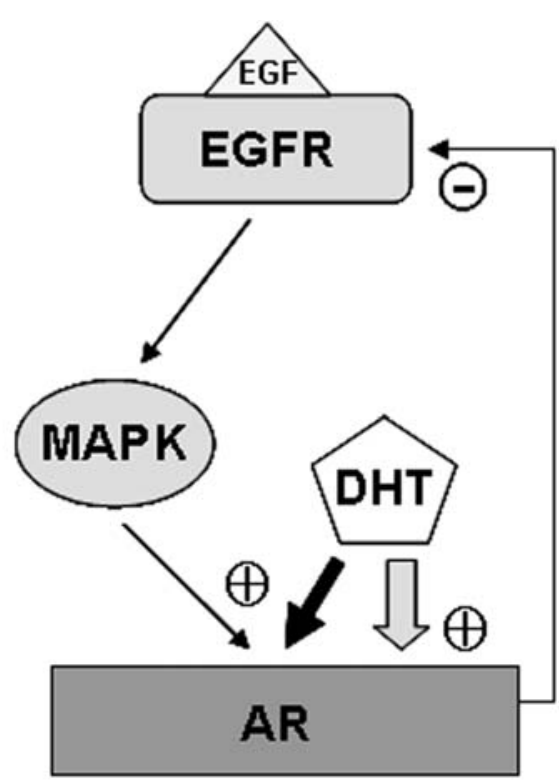

Figure 7. Model for the interaction of EGFR and AR signalling in prostate cancer cells. EGF and DHT synergistically activate the androgen receptor (black arrows). DHT-treatment, upon prolonged treatment, results in increase of AR protein levels (open arrow) and in decrease of EGFR levels.

treatment with DHT and MG-132 resulted in a stronger EGFR ubiquitination signal suggesting an accumulation of ubiquitinated EGFR due to inhibition of degradation. FL treatment reduced both basal EGFR ubiquitination and ubiquitination induced by DHT. The results clearly show that DHT enhances degradation of EGFR.

DHT treatment increases AR protein levels. To assess the role of DHT treatment on AR protein, LNCaP cells were treated with DHT (5 nM) for different the time-periods $\leq 48 \mathrm{~h}$. The results showed that DHT treatment significantly increased AR protein levels 2.3- and 4-fold at 24 and 48 h, respectively (Fig. 6).

\section{Discussion}

The different types of MAPK have been suggested to be necessary for early processes in prostate cancer (24). ERK1/2 and p38 are the major members of the MAPK family. It has been widely claimed that ERK activation contributes to cell differentiation, proliferation and survival (29) and p38 activation promotes apoptosis (30). However, many conflicting reports (22-24) demand further studies regarding the role of MAPK in prostate cancer. The MAPK pathway links EGFR-mediated signals to nuclear events affecting cellular processes related to growth, mitosis, differentiation and death (31) and in prostate cancer, ErbB2 (HER2/neu) was reported to induce AR activation through the MAPK signalling cascade even without androgen stimulation (32). Therefore, we first investigated the effects of EGF alone and in combination with DHT treatment on phosphorylation of ERK1/2 and p38 and on activation of the androgen receptor in our experimental system. Although DHT-treatment alone did not induce ERK $1 / 2$ phosphorylation and EGF-treatment alone did not result in AR activation in LNCaP cells, there was a clear synergistic effect on AR activation upon combination treatment with DHT and EGF. The observation that the MEK inhibitor U0126 completely inhibited DHT- and DHT/EGFinduced AR activation clearly documents the role of ERK1/2 in DHT-induced AR activation.

The role of p38 seems to be more complex. Although treatment of the LNCaP cells with DHT resulted in marked inhibition of EGF-induced p38 phosphorylation, DHT/EGFinduced AR activity was significantly stronger as compared to treatment with DHT or EGF, respectively. While pp38 may be dephosphorylated (inactivated) in conditions resulting in AR activation, inhibition of this enzyme by SB 203580 surprisingly resulted in inhibition of AR activation by DHT. This paradoxical finding suggests complex mechanisms of interaction of p38 with AR function. Although p38 was claimed as apoptotic inducer by some authors $(19,22,33)$, our findings agree with reports that p38 is directly involved in AR-mediated cell proliferation, survival and growth since AR transactivation results in cell proliferation in $\mathrm{LNCaP}$ cells (4).

The observation of a synergistic effect of DHT and EGF on AR activity is supported by the findings of Jones et al (34) who reported that combined treatment with EGF and $5 \alpha$-DHT produced an additive effect on cell proliferation. However, the molecular basis of the interactions between DHT and EGF in prostate cancer remains unclear. It has been reported that androgen regulates EGFR receptor expression in endometrial cells (35) and DHT inactivates prostatic acid phosphatase which causes stimulation of EGF signal pathway $(36,37)$. Thus, the molecular basis of EGF/DHT synergism may be a future topic of interest.

The role of androgen in the control of AR protein levels as available in the literature is conflicting. Upon androgen treatment, an increase in total AR protein content (38), posttranslational modification without alteration at the AR protein level (39) or stabilization of the AR protein $(40,41)$ have been reported. Yeap et al showed that DHT decreased total AR mRNA, but increased AR protein (42). Androgenmediated negative autoregulation of AR mRNA has been 
reported by many authors $(38,39,43)$, and androgen-induced AR mRNA transcription has been suggested to increase paradoxically AR mRNA stability (39), which in turn might lead to increased AR protein in LNCaP cells exposed to DHT for $24 \mathrm{~h}$ and more. Although we did not study AR mRNA levels, we found that DHT-treatment of LNCaP cells for $24 \mathrm{~h}$ and $48 \mathrm{~h}$ resulted in significant increase of AR protein levels.

It was reported that prolonged treatment of prostate cancer cells with androgens results in down-regulation of EGFR protein levels. Incubation with $1 \mathrm{nM}$ DHT for 15 days reduced the EGFR protein in DU145-AR cells (DU145 prostate cancer cells stably transfected with AR cDNA) (25). This agrees with our findings where treatment with $5 \mathrm{nM}$ DHT for $24 \mathrm{~h}$ reduced EGFR protein significantly in LNCaP cells. The DHT-dependence of down-regulation of the AR protein is supported by the observation that the anti-androgen FL was able to rescue EGFR protein. We conclude that EGFR protein down-regulation is the result of exposure of the cells to DHT. This finding may be of importance for therapy of androgendependent prostate cancer. Anti-androgenic therapy may result in maintenance of the EGFR signalling properties of the cancer cells and hence in sustained stimulation of proliferation by EGF or TGF $\alpha$.

Finally, we were interested in the mechanism involved in DHT mediated down-regulation of EGFR protein in LNCaP cells. In our experiment polyubiquitination of EGFR protein was found increased in immunoprecipitates from DHT-treated cells, and especially from MG-132 and DHT/MG-132 treated cells. This suggests proteasomal degradation of EGFR as a result of prolonged androgen exposure. However, it was reported, that EGFR as such is not a target for proteasomal degradation (44), but ubiquitinated EGFR is removed from the cells via endocytosis and subsequent degradation in lysosome (45). MG-132 has further been reported to decrease transcriptional activity of AR by eliminating androgeninduced nuclear translocation and co-activator recruitment $(46,47)$. Thus, DHT-mediated polyubiquitination and proteasomal degradation of EGFR might be controlled through mechanism(s) other than increased AR level. However, although it is not known whether the DHT-related increased AR protein levels are involved in the process of EGFR degradation, it may be concluded that prolonged exposure of LNCaP cells to DHT activates a regulatory loop that modulates cellular EGFR levels.

In conclusion, our results suggest a complex regulatory loop between AR and EGFR function and expression levels in AR-positive prostate cancer cells. Fig. 7 summarizes the findings in a simple model. We suggest that both ERK1/2 and p38 MAP kinases are involved in androgen-dependent AR activation in LNCaP cells and EGF and DHT show a synergistic positive effect on AR transactivation. Long-term $\mathrm{AR}$ activation increases the AR protein level and decreases the EGFR protein level.

\section{Acknowledgements}

B. Mukherjee is a recipient of the long-term Overseas Biotechnology Research Associateship (Government of India), (grant no. BT/IN/BTOA/05/2005).

\section{References}

1. Grönberg H: Prostate cancer epidemiology. Lancet 361: 859-864, 2003.

2. Denmeade SR, Lin XS and Isaacs JT: Role of programmed (apoptotic) cell death during the progression and therapy for prostate cancer. Prostate 28: 251-265, 1996.

3. Blok LJ, De Ruiter PE and Brinkmann AO: Forskolin-induced dephosphorylation of the androgen receptor impairs ligand binding. Biochemistry 37: 3850-3857, 1998.

4. Edwards $J$ and Bartlett JMS: The androgen receptor and signaltransduction pathways in hormone-refractory prostate cancer. part 1: modifications to the androgen receptor. BJU Int 95: 1320-1326, 2005.

5. Culig Z, Klocker H, Bartsch G and Hobisch A: Androgen receptors in prostate cancer. Endocr Relat Cancer 9: 155-170, 2002.

6. Di Loreto G, Tortora G and D'Armiento FP: Expression of epidermal growth factor receptor correlates with disease relapse and progression to androgen-independence in human prostate cancer. Clin Cancer Res 8: 3438-3444, 2002.

7. Roberts RB, Min L, Washington MK, Olsen SJ, Settle SH, Coffey RJ and Thereadgill DW: Importance of epidermal growth factor receptor signaling in establishment of adenomas and maintenance of carcinomas during intestinal tumorigenesis. Proc Natl Acad Sci USA 99: 1521-1526, 2002.

8. Alper O, Bergmann-Leitner ES, Bennett TA, Hacker NF, Stromberg K and Stetler-Stevenson WG: Epidermal growth factor receptor signaling and the invasive phenotype of ovarian carcinoma cells. J Natl Cancer Inst 93: 1375-1384, 2001.

9. Kim HG, Kassis J, Souto JC, Turner T and Wells A: EGF receptor signalling in prostate morphogenesis and tumorigenesis. Histol Histopathol 14: 1175-1182, 1999.

10. Gschwind A, Fischer OM and Ullrich A: The discovery of the receptor tyrosine kinases: targets for cancer therapy. Nat Rev Cancer 4: 361-370, 2004.

11. Liu Y, Majumder S, McCall W, Sartor CI, Mohler JL, Gregory CW, Earp HS and Whang YE: Inhibition of HER-2/neu kinase impairs androgen receptor recruitment to the androgen responsive enhancer. Cancer Res 65: 3404-3409, 2005.

12. Kharait S, Dhir R, Lauffenburger D and Wells A: Protein kinase Co signaling downstream of the EGF receptor mediates migration and invasiveness of prostate cancer cells. Biochem Biophys Res Commun 343: 848-856, 2006.

13. Kambhampati S, Ray G, Sengupta K, Reddy VP, Banerjee SK and Veldhuizen PJV: Growth factors involved in prostate carcinogenesis. Front Biosci 10: 1335-1367, 2005.

14. Tyagi A, Agarwal R and Agarwal C: Grape seed extract inhibits EGF-induced and constitutively active mitogenic signaling but activates JNK in human prostate carcinoma DU145 cells: possible role in antiproliferation and apoptosis. Oncogene 22: 1302-1316, 2003.

15. Feldman BJ and Feldman D: The development of androgenindependent prostate cancer. Nat Rev Cancer 1: 34-45, 2001.

16. Hofer DR, Sherwood ER, Bromberg WD, Mendelsohn J, Lee C and Kozlowski JM: Autonomous growth of androgen-independent human prostatic carcinoma cells: role of transforming growth factor alpha. Cancer Res 51: 2780-2785, 1991.

17. Saga K and Jimbow K: Immunohistochemical localization of activated EGF receptor in human eccrine and apocrine sweat glands. J Histochem Cytochem 49: 597-601, 2001.

18. Sheikh SSE, Domin J, Abel P, Stamp G and Lalani E: Phosphorylation of both EGFR and ErbB2 is a reliable predictor of prostate cancer cell proliferation in response to EGF. Neoplasia 6: 846-853, 2004.

19. Shimada K, Nakamura M, Ishida E, Kishi M and Konishi N: Roles of p38- and c-jun NH2-terminal kinase-mediated pathways in 2-methoxyestradiol-induced p53 induction and apoptosis. Carcinogenesis 24: 1067-1075, 2003.

20. Gioeli D, Mandell JW, Petroni GR, Frierson HF Jr and Weber MJ: Activation of mitogen-activated protein kinase associated with prostate cancer progression. Cancer Res 59: 279-284, 1999.

21. Paweletz CP, Charboneau L, Bichsel VE, Simone NL, Chen T, Gillespie JW, Emmert-Buck MR, Roth MJ, Petricoin IE and Liotta LA: Reverse phase protein microarrays which capture disease progression show activation of pro-survival pathways at the cancer invasion front. Oncogene 20: 1981-1989, 2001.

22. Davoodpour P and Landstrom M: 2-Methoxyestradiol-induced apoptosis in prostate cancer cells requires Smad7. J Biol Chem 280: 14773-14779, 2005. 
23. Ricote M, Garcia-Tunon I, Fraile B, Fernandez C, Aller P, Paniagua R and Royuela M: P38 MAPK protects against TNF-alpha-provoked apoptosis in LNCaP prostatic cancer cells. Apoptosis 11: 1169-1975, 2006.

24. Shimada K, Nakamura M, Ishida E and Konishi N: Molecular roles of MAP kinases and FADD phosphorylation in prostate cancer. Histol Histopathol 21: 415-422, 2006.

25. Gravina GL, Festuccia C, Angelucci A, Poletti A, Capuano D, Vicentini C, Motta M and Bologna M: Long-term presence of androgens and anti-androgens modulate EGF-receptor expression and MAP-kinase phosphorylation in androgen receptor-prostate positive cancer cells. Int J Oncol 25: 97-104, 2004.

26. Schmitt M, Klinga K, Schnarr B, Morfin R and Mayer D: Dehydroepiandrosterone stimulates proliferation and gene expression in breast cancer cells after conversion to estradiol. Mol Cell Endocrinol 173: 1-13, 2001.

27. Medunjanin S, Hermani A, De Servi B, Grisouard J, Rincke G and Mayer D: Glycogen synthase kinase-3 interacts with and phosphorylates estrogen receptor- $\alpha$ and is involved in the regulation of receptor activity. J Biol Chem 280: 33006-33014, 2005.

28. Fan M, Nakshatri $\mathrm{H}$ and Nephew KP: Inhibiting proteasomal proteolysis sustains estrogen receptor- $\alpha$ activation. Mol Endrocrinol 18: 2603-2615, 2004

29. Xia Z, Dickens M, Raingeaud J, Davis RJ and Greenberg ME: Opposing effects of ERK and JNK-p38 MAP kinases on apoptosis. Science 270: 1326-1331, 1995.

30. Wilkinson MG and Millar JB: SAPKs and transcription factors do the nucleocytoplasmic tango. Genes Dev 12: 1391-1397, 1998.

31. Reddy KB, Nabha SM and Atanaskova N: Role of MAP kinases in tumor progression and invasion. Cancer Metastasis Rev 22: 395-403, 2003.

32. Yeh, S, Lin HK, Kang HY, Thin, TH, Lin MF and Chang C; From HER2/Neu signal cascade to androgen receptor and its coactivators: a novel pathway by induction of androgen target gene through MAP kinase in prostate cancer cells. Proc Natl Acad Sci USA 96: 5458-5463, 1999.

33. Tanka Y, Gavrielides MV, Mitsuuchi Y, Fujii T and Kazanietz MG: Protein kinase C promotes apoptosis in LNCaP prostate cancer cells through activation of p38 MAPK and inhibition of the Akt survival pathways. J Biol Chem 278: 33753-33762, 2003.

34. Jones HE, Barrow D, Dutkowski CM, Goddard L, Smith C, Harper ME and Nicholson RI: Effect of an EGF-R selective tyrosine kinase inhibitor and an anti-androgen on LNCaP cells: identification of divergent growth regulatory pathways. Prostate 49: 38-47, 2001.
35. Watson H, Franks S and Bonney RC: Regulation of epidermal growth factor receptor by androgens in human endometrial cells in culture. Hum Reprod 13: 2585-2591, 1998.

36. Lin MF, Meng TC, Rao PS, Chang C, Schonthal AH and Lin FF: Expression of human prostatic acid phosphatase correlates with androgen-stimulated cell proliferation in prostate cancer cell lines. J Biol Chem 273: 5939-5947, 1998.

37. Zelivianski S, Larson C, Seberger J, Taylor R and Lin MF: Expression of human prostatic acid phosphatase gene is regulated by upstream negative and positive elements. Biochim Biophys Acta 1491: 123-132, 2000.

38. Krongard A, Wilson CM, Wilson JD, Allman DR and McPhaul MJ: Androgen increases androgen receptor protein while decreasing receptor mRNA in LNCaP cells. Mol Cell Endocrinol 76: 79-88, 1991.

39. Wolf DA, Herzinger T, Hermeking H, Blaschke D and Horz W: Transcriptional and posttranscriptional regulation of human androgen receptor expression by androgen. Mol Endocrinol 7: 924-936, 1993.

40. Kemppainen JA, Lane MV, Sar M and Wilson EM: Androgen receptor phosphorylation, turnover, nuclear transport, and transcriptional activation: specificity for steroids and antihormones. J Biol Chem 267: 968-974, 1992

41. Zhou ZX, Lane MV, Kemppainen JA, French FS and Wilson EM: Specificity of ligand-dependent androgen receptor stabilization: receptor domain interactions influence ligand dissociation and receptor stability. Mol Endocrinol 9: 208-218, 1995.

42. Yeap BB, Roman GK and Leedman PJ: Differential posttranscriptional regulation of androgen receptor gene expression by androgen in prostate and breast cancer cells. Endocrinology 140: 3282-3291, 2006.

43. Quarmby VE, Yarbrough WG, Lubhan DB, French FS and Wilson EM: Autologous down-regulation of androgen receptor messenger ribonucleic acid. Mol Endocrinol 4: 22-28, 1990.

44. Longva KE, Blystad FD, Stang E, Larsen AM, Johannessen LE and Madshus IH: Ubiquitination and preteasomal activity is required for transport of the EGF receptor to inner membranes of multivesicular bodies. J Cell Biol 156: 843-854, 2002.

45. Dikic I: Mechanisms controlling EGF receptor endocytosis and degradation. Biochem Soc Trans 31: 1178-1181, 2003.

46. Kanz Z, Pirskanen A, Janne OA and Palvimo JJ: Involvement of proteasome in the dynamic assembly of the androgen receptor transcription complex. J Biol Chem 277: 48366-48371, 2002.

47. Lin HK, Altuwaijri S, Lin WJ, Kan PY, Collins LL and Chang C: Proteasome activity is required for androgen receptor nuclear translocation and interaction with coregulators in prostate cancer cells. J Biol Chem 277: 36570-36576, 2006. 